\title{
Investigation of Nonlinear Creep Behaviour of Millettia Laurentii Wood Through Zener Fractional Rheological model
}

\section{Atchounga Kuida Prisca ( $\square$ patchoungakuida@yahoo.com )}

Universite de Dschang Faculte des Sciences https://orcid.org/0000-0003-4312-4479

Njankouo Jacques Michel

University of Yaounde I: Universite de Yaounde I

Foadieng Emmanuel

University of Buea

Talla Pierre Kisito

University of Dschang: Universite de Dschang

Original Article

Keywords: Wood, Millettia Laurentii, Creep, Fractional derivatives, Spring-pot, Fractional model

Posted Date: May 18th, 2021

DOI: https://doi.org/10.21203/rs.3.rs-522827/v1

License: (c) (i) This work is licensed under a Creative Commons Attribution 4.0 International License.

Read Full License 


\title{
Investigation of nonlinear creep behaviour of Millettia Laurentii Wood through Zener fractional rheological model

\author{
Atchounga Kuida Prisca ${ }^{1,3^{*}}$, Njankouo Jacques Michel ${ }^{1}$, \\ Foadieng Emmanuel $^{2}$ and Talla Pierre Kisito ${ }^{3}$ \\ University of Yaoundé I, Higher Technical Teacher Training College (HTTTC), \\ Wood Engineering Department, Ebolowa, Cameroon ${ }^{1}$ \\ University of Buéa, Higher Technical Teacher Training College (HTTTC), \\ Civil Engineering Department, Kumba, Cameroon ${ }^{2}$ \\ University of Dschang, Physics Department, Mechanics and Modeling of \\ Physical Systems Research Unit (UR-2MSP), Dschang, Cameroon ${ }^{3}$ \\ "Correspondence: patchoungakuida@yahoo.com
}

\begin{abstract}
Nowadays one of the principal difficulties that wood structural development and construction have to face is wood creep. Nevertheless, the secret to master and solve the creep deformation of wood relies on a sensible and exact rheological model for numerical analysis. In this research work our goal is to study the nonlinear creep behaviour of the Cameroonian wood species Millettia Laurentii known as Wengé wood through fractional calculus approach. So, we have conducted a nonlinear creep constitutive model of Millettia Laurentii wood, that is the Zener fractional rheological model, and the parameters of this model have been determined. We have studied the influence of stress level $\sigma$ and fractional order $\mathrm{n}$ on the Millettia Laurentii wood creep process by a sensitivity analysis of the model parameters. The outcomes of this sensitivity analysis are of paramount importance because they can be used in reality to inspect the creep process and deformation amount of Millettia Laurentii wood in practical engineering. Moreover, guidance for the secure construction of Millettia Laurentii wood engineering can be given by the means of the findings of this research.
\end{abstract}

Keywords: Wood; Millettia Laurentii; Creep; Fractional derivatives; Spring-pot; Fractional model.

\section{Introduction}

The phenomenon in which wood deformation increases with time under long-term external load is known as wood creep. The development of creep increases the loss of stress in the structure of wood. It also redistributes the internal force of static and statically indeterminate structures, resulting in excessive structural deformation, a significant reduction in overall strength, and even a loss of bearing capacity [1]. The internal energy of wood structures is also redistributed by this phenomenon, as a result: the deformation of the structure is increased, the strength is significantly reduced, and the bearing capacity of the structure is negatively impacted [1]. With the increasingly use of wood materials in civil engineering structures, wood creep appears as one of the principal issues that affect the development of wood structures, the security of wood constructions and their long-term stability [2-6]. In the particular case of wood material, the nonlinearity in wood behaviour can be observed at 
both lower and higher stress levels [7]. A lot of linear models have been proposed in order to simulate creep behaviour of wood [8-13]. Meanwhile, the study of nonlinear creep behaviour of wood is very complex because this material is assimilated to a certain extend as a composite material. The basic Maxwell model is referenced to propose the linearized mathematical modelling of the geometric nonlinearity theory [14-16]. But wood creep cannot be described accurately with the mentioned model. Some research works have been devoted to the nonlinear creep behaviour of wood under high stresses [17-21]. Fractional derivative is a temporal differentiation operator that can allow following the evolution of a function varying with time [22]. The theory of fractional calculus is widely used in the domain of material sciences [23-24], and fractional derivative has been introduced to establish a viscoelastic rheological model that simulates the viscoelastic behaviour and the mechanical response of a material [25-28]. Millettia Laurentii (Wengé) wood is one of the oldest building materials used by humans in the south region of Cameroon and in many sub-Saharan African countries. Some research works have been devoted to the study of mechanical and physical properties of this wood [29, 30], but this remains insufficient to well characterise this wood material. Therefore, further studies are necessary to promote this material in the modern world. So, it is urgent to study its creep behaviour to have an idea about the load bearing capacity of Millettia Laurentii (Wengé) wood. To achieve this goal in the current research work, the fractional rheological model of Zener is proposed.

\section{Materials and methods}

\subsection{The spring-pot}

Let's use the fractional calculus operator, then equation (1) below is the constitutive equation of the Spring-pot (fig. 1b).

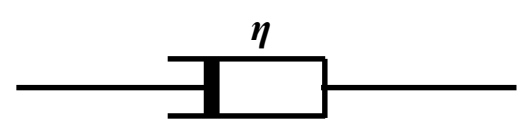

(a)

Figure 1 (a): Newton dashpot ;

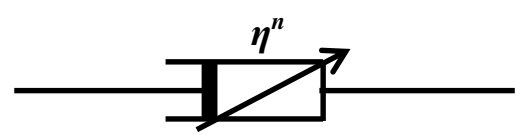

(b)

$$
\sigma(t)=\eta^{n} D_{t}^{n}[\varepsilon(t)], 0 \leq n \leq 1
$$

where $\boldsymbol{\eta}^{n}$ is the viscosity coefficient, $\boldsymbol{n}$ the order of the fractional derivative, and $D_{t}^{n}$ indicates fractional differentiation.

$$
D_{t}^{n}[\varepsilon(t)]=D D_{t}^{n-1}[\varepsilon(t)]
$$

where D indicates differentiation and the operation $D_{t}^{n-1}$ can be expressed as a Riemann-Liouville fractional integral, i.e.,

$$
D_{t}^{n-1}[\varepsilon(t)]=\int_{0}^{t} \frac{(t-\tau)^{-n}}{\Gamma(1-n)} \varepsilon(\tau) d \tau,
$$

with $\Gamma$ the gamma function. 
Actually, the spring-pot is a fractional derivative description of the Newtonian dashpot. The special cases of Eq. (1) are a simple spring element when $\mathrm{n}=0$, representing an ideal solid, and a Newtonian dashpot behavior when $\mathrm{n}=1$, representing an ideal fluid. When $0<\mathrm{n}<1$, the spring-pot exhibits characteristics of both a spring and a Newtonian dashpot.

Letting the stress $\sigma(\mathrm{t})$ be constant $(\sigma(\mathrm{t})=\sigma)$ in Eq. (1) and taking fractional integral calculation of the equation on the basis of the Riemann-Liouville operator, we obtain the constitutive relation of the spring-pot [31] :

$\varepsilon(t)=\frac{\sigma}{\eta^{n} \times \Gamma(1+n)} t^{n}, \quad(0 \leq n \leq 1)$

\subsection{Establishment of fractional derivative model of wood creep}

The classical Zener model was regarded as one that can approach the first stage and the second stage of both steady and unsteady situations. By replacing the Newtonian dashpot in the classical Zener model with the spring-pot, a new creep constitutive model, referred to as the time-based fractional derivative approach, is proposed, which is composed of the Hooke body and the viscoelastic body (fig. 2).

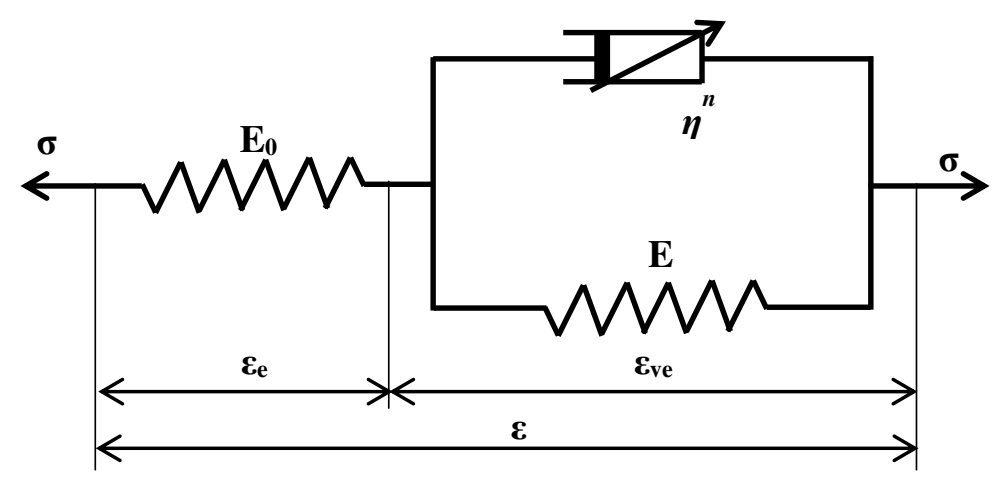

Figure 2 : Fractional rheological Zener model

The total strain in fig. 2 is given by:

$\varepsilon=\varepsilon_{e}+\varepsilon_{v e}$

where $\varepsilon_{\mathrm{e}}$ and $\varepsilon_{\mathrm{ve}}$ are the strains of Hooke body and viscoelastic body, respectively.

For the Hooke body, the constitutive relation is given by

$\varepsilon_{e}=\frac{\sigma}{E_{0}}$

where $\mathbf{E}_{\boldsymbol{0}}$ is the elastic modulus as shown in fig. $\mathbf{2}$ and $\boldsymbol{\sigma}$ the applied stress.

For the viscoelastic body, the constitutive relation is given by:

$\varepsilon_{v e}=\frac{\sigma}{\eta^{n}} \sum_{k=0}^{\infty} \frac{(-1)^{k}\left(\frac{E}{\eta^{n}}\right)^{k} t^{n(1+k)}}{n(1+k) \Gamma[n(1+k)]}$ 
where $\mathbf{E}$ stands for the elastic modulus, and $\boldsymbol{\eta}^{n}$ is the viscosity coefficient of the spring-pot.

By substituting Eqs. (6) and (7) into Eq. (5), we obtain the total creep strain of the time-based fractional derivative model shown in fig. $\mathbf{2}$ as below:

$\varepsilon(t)=\frac{\sigma}{E_{0}}+\frac{\sigma}{\eta^{n}} \sum_{k=0}^{\infty} \frac{(-1)^{k}\left(\frac{E}{\eta^{n}}\right)^{k} t^{n(1+k)}}{n(1+k) \Gamma[n(1+k)]}$

\subsection{Experimental setup}

The efficacy of the fractional derivative model is dependent on its ability to adequately fit experimental data. The current experiments were carried out at Dschang University (Cameroon) using a four points flexural test machine (Fig. 4) coupled with a strain-bridge possessing a high accuracy. The indoor temperature was $23^{\circ} \mathrm{C}$ and the relative humidity was $65 \%$ during all the process. All the wood samples were extracted from the same billet of Millettia Laurentii wood, originating from KyéOssi natural forest in Cameroon south region. The specimens were prepared with a required dimension of $20 \mathrm{~mm} \times 20 \mathrm{~mm} \times 360 \mathrm{~mm}$ (fig. 3 ).

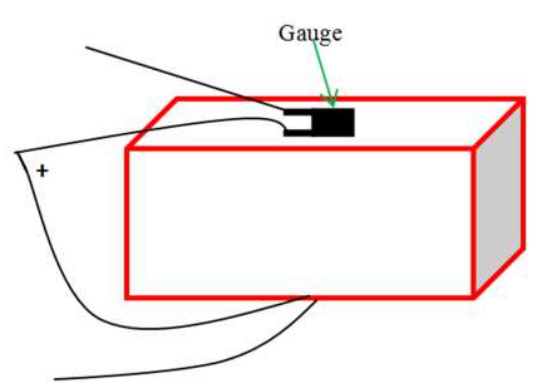

Figure 3 : Sample carrying two gauges.

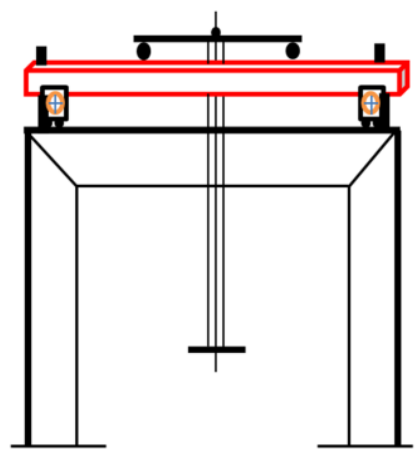

Figure 4 : Creep test machine

During the test the sample (Fig. 3) is laid on the test machine in such a way that one gauge is on the top measuring the traction of the wood fibers and another one symmetrically on the opposite face of the sample (Fig. 4) evaluating the compression of the wood fibers. The wood specimens were tested under four points flexural loading following the French Norm NF B 51-003 that labels general requirements for physical and mechanical tests.

\section{Results and discussion}

\subsection{Determination of parameters of fractional derivative model}

The parameter $\boldsymbol{E}_{\boldsymbol{0}}$ is the Young modulus, it is calculated by the means of initial instantaneous elastic strain at the loading time of the wood sample. The expression of $\boldsymbol{E}_{\boldsymbol{0}}$ is as follows:

$E_{0}=\frac{\sigma}{\varepsilon_{0}}$

where $\boldsymbol{\sigma}$ is the initial stress, and $\boldsymbol{\varepsilon}_{\boldsymbol{0}}$ stands for the initial instantaneous elastic strain. 
In this work the model parameters $\boldsymbol{E}, \boldsymbol{\eta}$ and $\boldsymbol{n}$ were determined according to the LevenbergMarquardt algorithm; which is an optimization method whose the coming down direction is a combination between the directions of the gradient and Newton-Gauss algorithms. The main advantage of this optimization method being that the out coming optimized model parameters is of high accuracy.

\subsection{Verification of Millettia Laurentii nonlinear creep constitutive model}

\subsubsection{Experimental research on Millettia Laurentii creep under high stress}

A series of uniaxial flexural nonlinear creep tests under different stresses and maintaining 23 ${ }^{\circ} \mathrm{C}$ were carried out. The stress was controlled at 24,62 \% ABS (about 38,06 MPa) and 27,83\% ABS (about 43,03 MPa). The average modulus of elasticity was $21058 \mathrm{MPa}$ and the average density was $789 \mathrm{~kg} / \mathrm{m}^{3}$. The experimental curves are shown in figure 5 .
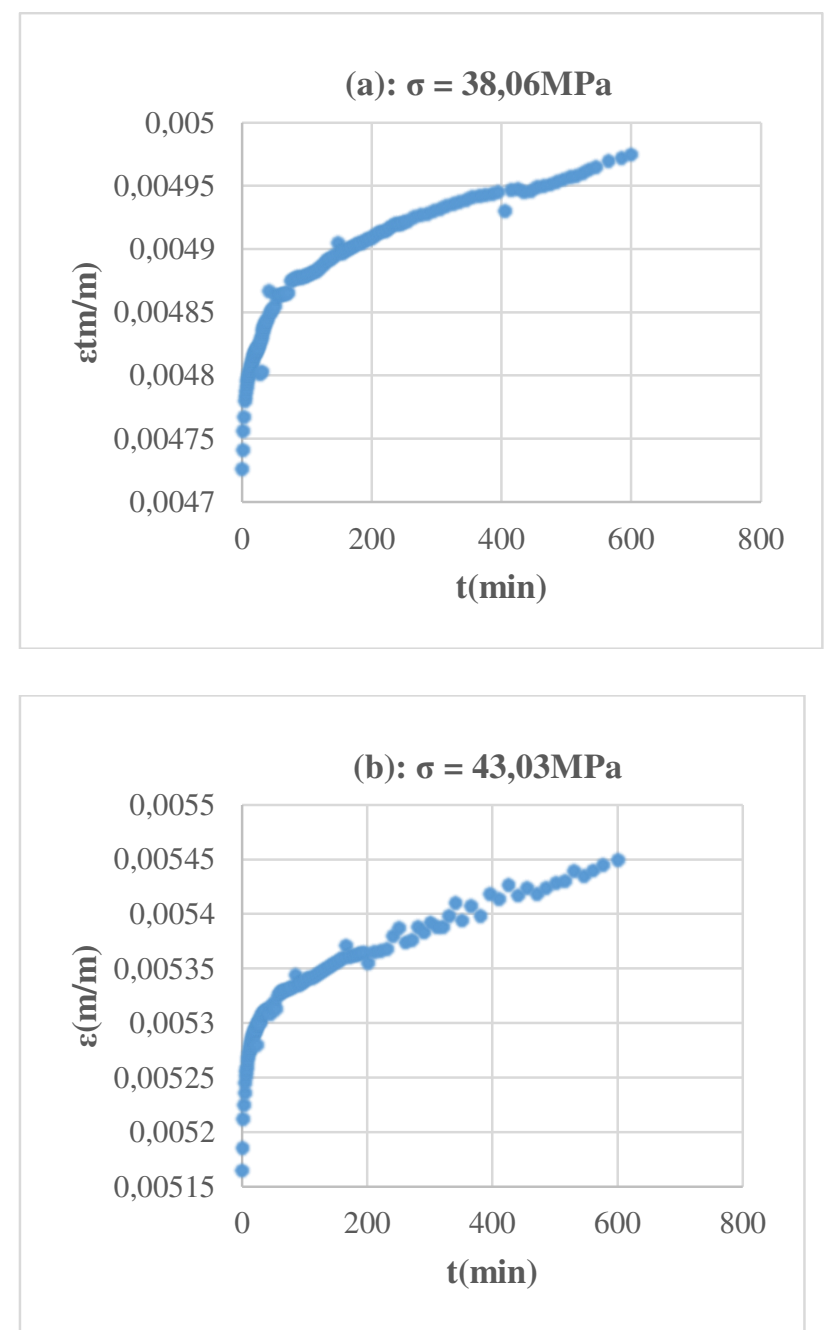

Figure 5: The curve of the wood creep tests under different stresses

As shown in Figure 5, the wood specimen nonlinear creep process can be divided into two stages under an uniaxial flexural of stress levels of 38,06 MPa and 43,03 MPa:

(1) the deceleration creep stage, with increasing strain and decreasing strain rate, 
(2) the isovelocity creep stage with constant strain rate.

The experimental curve characteristics can be described by using the elastomer and viscoelastic body in the model. Now, the parameters $\boldsymbol{E}_{\boldsymbol{0}}, \boldsymbol{E}, \boldsymbol{\eta}$ and $\boldsymbol{n}$ need to be solved. The Levenberg-Marquardt algorithm; which is an optimization method is carried out using the conducted model. The calculated model parameters are shown in Table 1, and the fitting results are shown in Figure 6. Accelerate creep has not occurred when the axial pressure is $38,06 \mathrm{MPa}$ and 43,03 $\mathrm{MPa}$, the wood creep process consists of deceleration and isometric creep.

Table 1: Parameter table of Wengé Wood creep model

\begin{tabular}{ccccc}
\hline$\sigma(\mathbf{M P a})$ & $E_{0}(\mathbf{M P a})$ & $E(\mathbf{M P a})$ & $\eta^{n}\left(\mathbf{M P a} \cdot \mathbf{m i n}^{\mathbf{n}}\right)$ & $n$ \\
\hline $\mathbf{3 8 , 0 6}$ & 8053,32 & 72789 & $1,034 \times 10^{6}$ & 0,335 \\
$\mathbf{4 3 , 0 3}$ & 8331,07 & 68594 & $1,028 \times 10^{6}$ & 0,334 \\
\hline
\end{tabular}

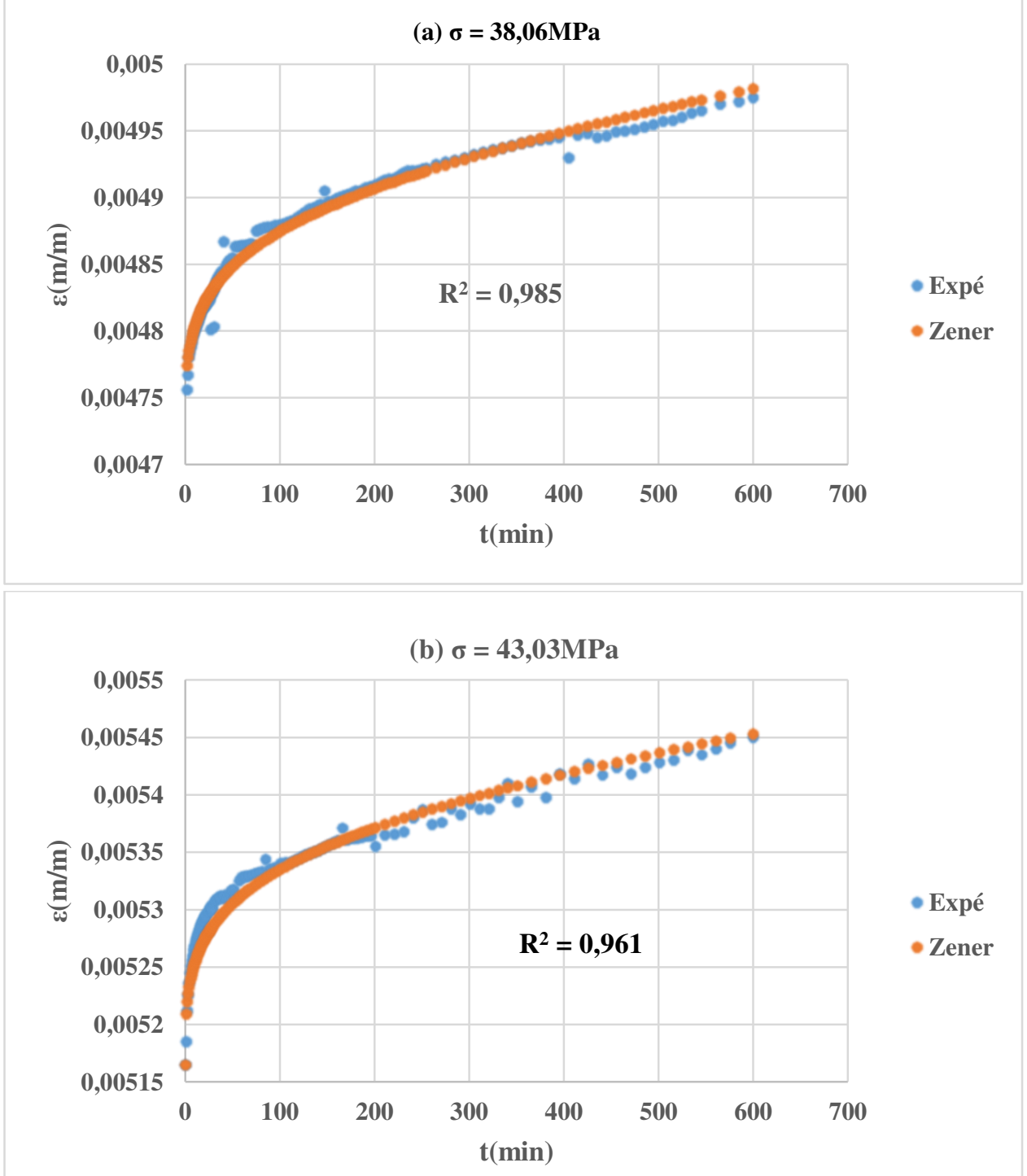

Figure 6: Experimental and Zener fractional forecasting curves at (a) 38,06 MPa et (b) 43,03 MPa

The fitting results show that the Millettia Laurentii wood deformation after loading can be correctly described by the constitutive model. Meanwhile, the initial creep of stage 1 and the steady creep of stage 2 can also be correctly expressed. 


\subsubsection{Millettia Laurentii creep under different stresses}

Flexural creep tests on Millettia Laurentii Wood specimens under different stresses have been carried out. The different applied stresses were respectively 16,55 MPa (10,70\% ABS), 23,17 MPa (14,98\% ABS) 28,13 MPa (18,19\% ABS), 33,1 MPa (21,41\% ABS). Each test lasted 10 hours that is 600 minutes, the resulting creep curves are depicted on figure 7 below:
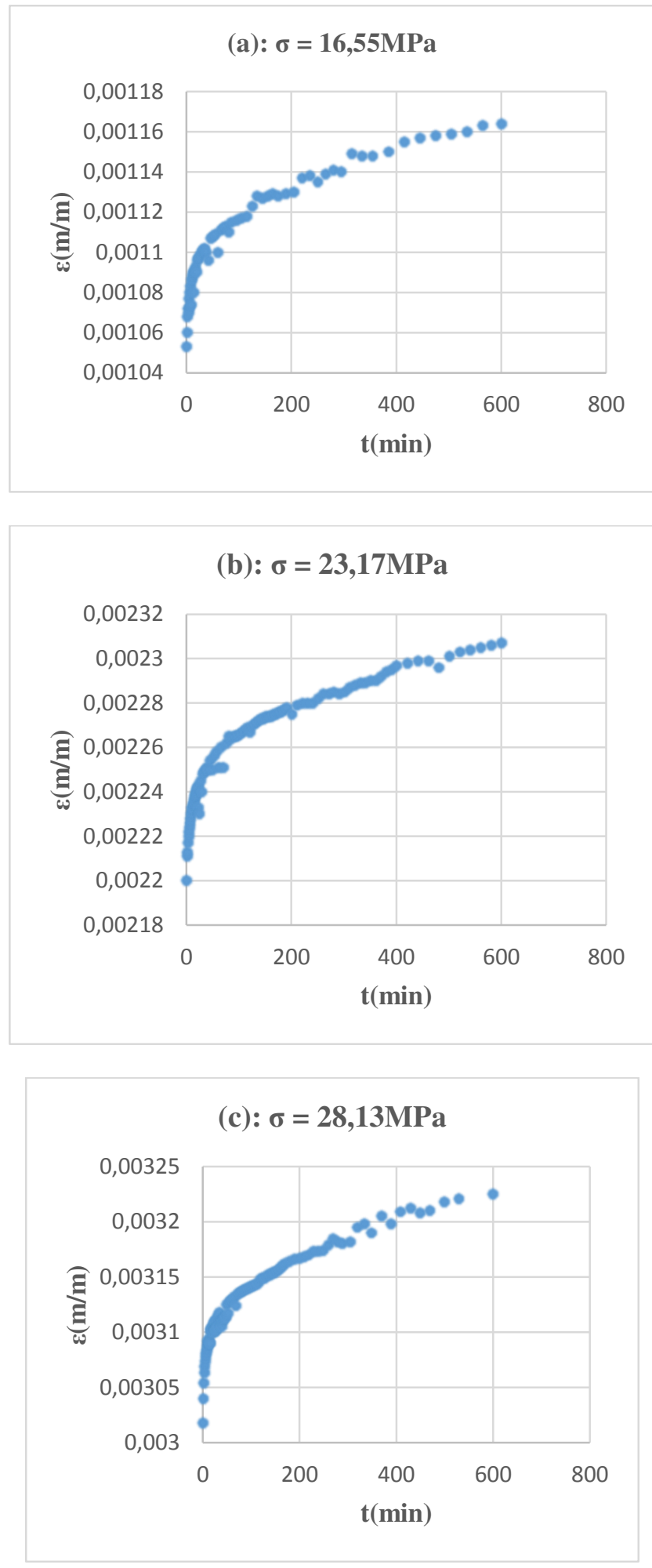


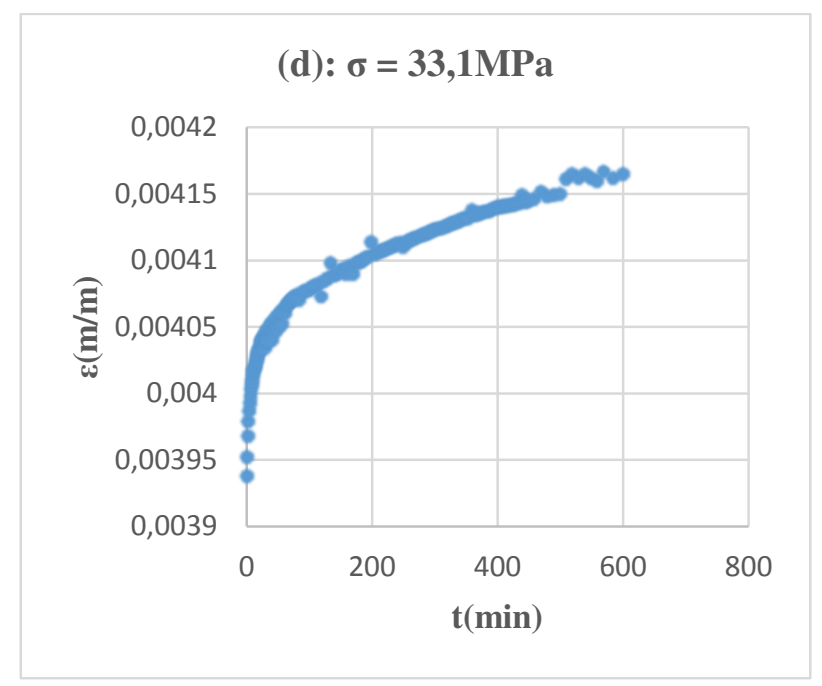

Figure 7: Courbes de fluage du bois Wengé sous différentes contraintes. (a) 16,55 MPa;

(b) 23,17 $\mathrm{MPa}$; (c) 28,13 MPa et (d) 33,1 MPa.

Under the four preceding mentioned stress levels, instantaneous elastic deformation appears first followed by primary creep characterized by an exponential decrease of creep rate; then stationary creep intervenes nearly at a constant creep rate. Characteristics of experimental curve can be described once more using a spring associated to a viscoelastic body in the model. Here, parameters $\mathrm{E}_{0}, \mathrm{E}, \eta$ and the fractional derivative order $\mathrm{n}$ are determined according to the curve characteristics. In the present work these parameters have been estimated through Levenberg-Marquardt optimisation method. The following table 2 presents values of the previous mentioned parameters. Experimental curves and forecasting curves are depicted in figure 8 .

Table 2 : Parameters of fractional Zener model for Millettia Laurentii

\begin{tabular}{ccccc}
\hline $\boldsymbol{\sigma}(\mathbf{M P a})$ & $E_{0}(\mathbf{M P a})$ & $E \mathbf{( M P a})$ & $\eta^{n}\left(\mathbf{M P a} \cdot \mathbf{m i n}^{\mathbf{n}}\right)$ & $n$ \\
\hline $\mathbf{1 6 , 5 5}$ & 15716,99 & 44853 & $1,512 \times 10^{6}$ & 0,390 \\
\hline $\mathbf{2 3 , 1 7}$ & 10531,82 & 74850 & $1,920 \times 10^{6}$ & 0,373 \\
\hline $\mathbf{2 8 , 1 3}$ & 9320,74 & 60034 & $1,055 \times 10^{6}$ & 0,359 \\
\hline $\mathbf{3 3 , 1}$ & 8405,28 & 65352 & $1,153 \times 10^{6}$ & 0,363 \\
\hline
\end{tabular}



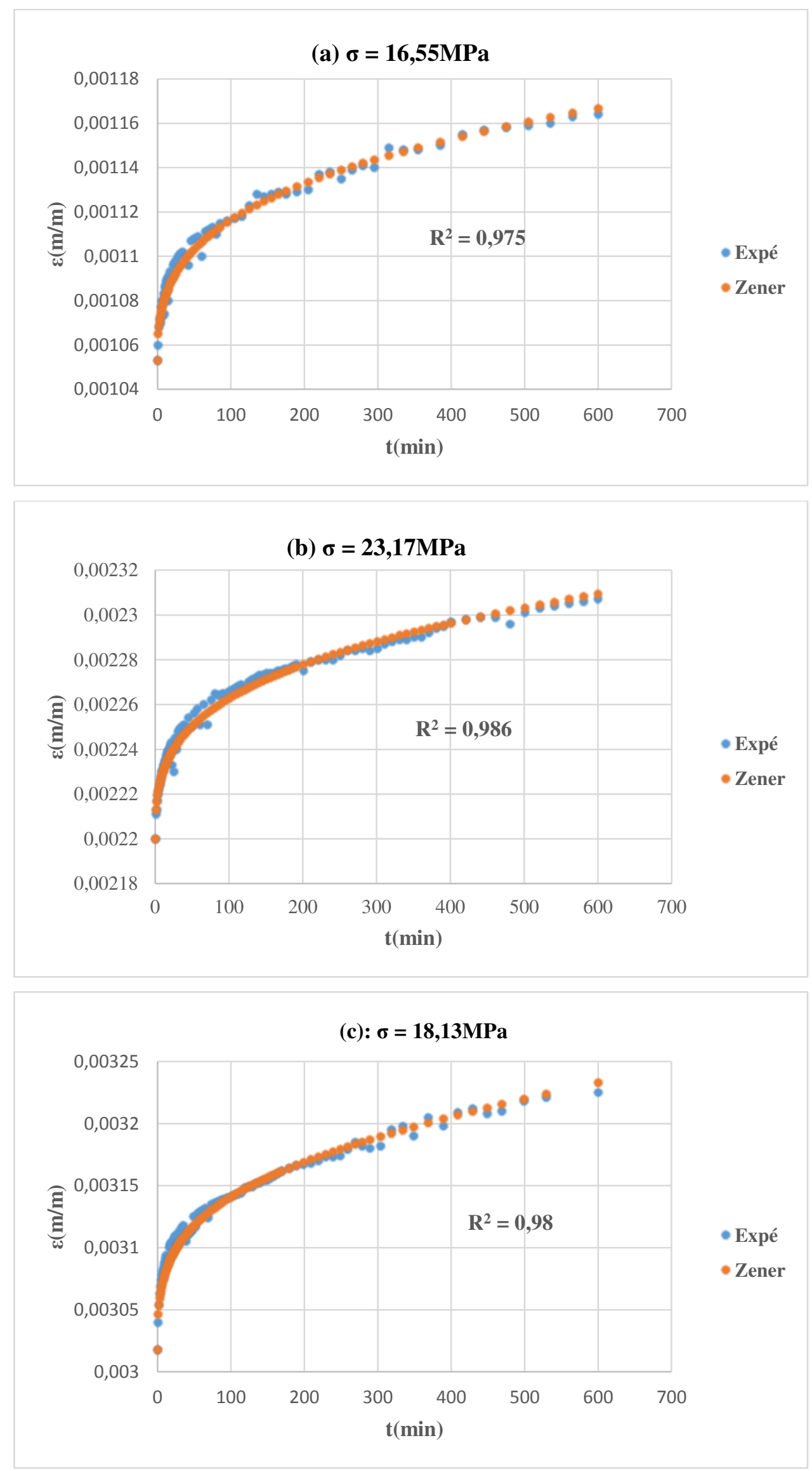


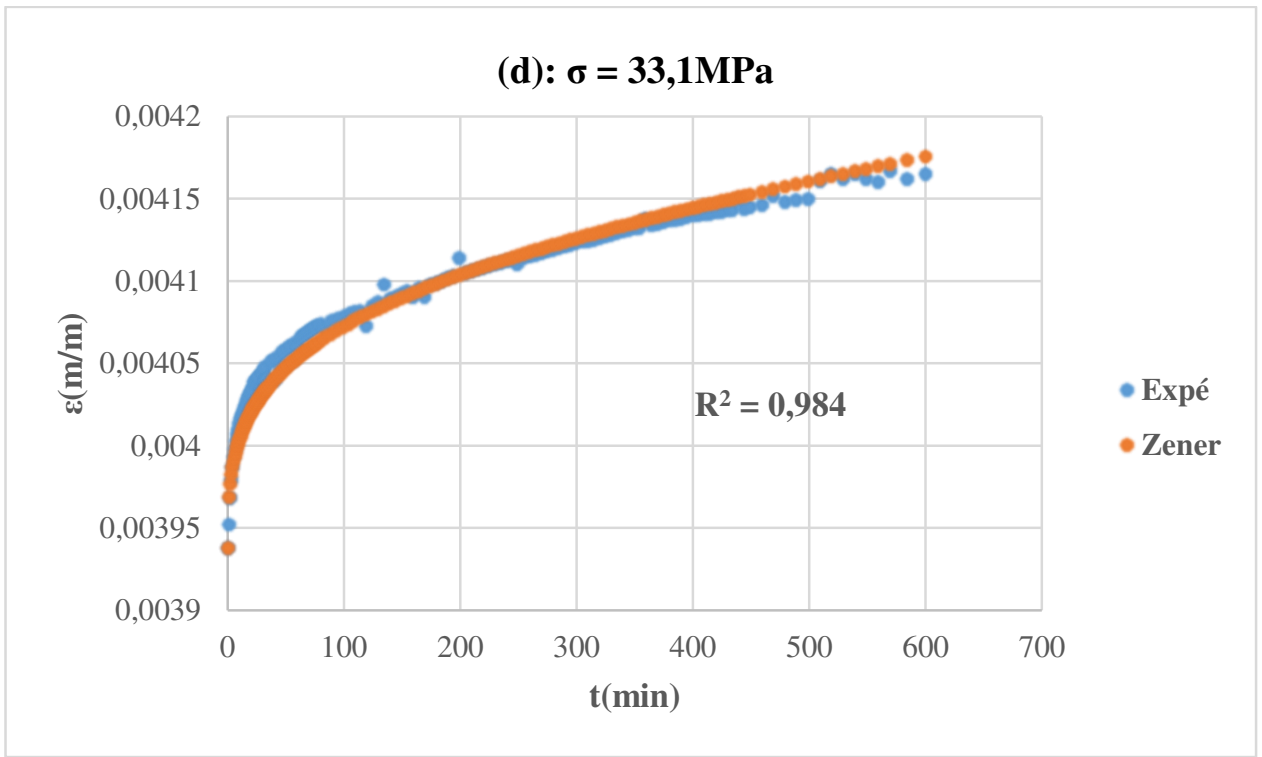

Figure 8: Experimental curves and forecasting curves of Millettia Laurentii wood. (a) 16,55 $\mathrm{MPa}$; (b) 23,17 MPa; (c) 28,13 MPa and (d) 33,1 MPa.

Wood creep curves obtained by Foadieng et al. [29] are similar to those mentioned in the present research work. The coefficient of determination in this paper $\left(\mathbf{R}^{\mathbf{2}} \mathbf{\mathbf { 0 } , 9 7}\right)$, is a proof of good correlation between fractional Zener model and the real behaviour of Millettia Laurentii wood, as we can see in table 2 and in figure 8. Fractional derivative Zener model represents primary and stationary creep of the studied wood species with a good precision. In sum, the validity of the model presented in the present work is confirmed by the good correlations obtained at different stress levels during the creep process of Millettia Laurentii. In the same vein, the application of fractional calculus theory to improve creep traditional models is also well addressed, given that fractional theory has become one of the most indicated means to study the nonlinearity of creep of wood material. The outcomes of this research work are in accordance with the findings of Brokans \& Ozola [19].

\section{Parameter sensitivity analysis of Millettia Laurentii nonlinear creep model}

Creep process of Millettia Laurentii is mainly influenced by parameters $\sigma$ and $n$, these parameters are obtained by analysing experimental and theoretical curves. Consequently, the study of their influence will be done through variable control method in order to appreciate the effect of the underlined parameters on the creep process of Millettia Laurentii. The model parameters are: $\sigma=$ $33,1 \mathrm{MPa} ; \mathrm{E}_{0}=8405,28 \mathrm{MPa} ; \mathrm{E}=65352 \mathrm{MPa} ; \eta^{\mathrm{n}}=1,153 \times 10^{6} \mathrm{MPa} \cdot \min ^{\mathrm{n}}$ and $\mathrm{n}=0,363$.

\subsection{Influence of the stress level $\sigma$}

Let's introduce parameters $\mathrm{E}_{0}=8405,28 \mathrm{MPa} ; \mathrm{E}=65352 \mathrm{MPa} ; \eta^{\mathrm{n}}=1,153 \times 10^{6} \mathrm{MPa} \cdot \mathrm{min}^{\mathrm{n}}$ and $\mathrm{n}=$ 0,363 into equation (8). The different stress levels are: $32,7 \mathrm{MPa} ; 32,9 \mathrm{MPa} ; 33,1 \mathrm{MPa} ; 33,3 \mathrm{MPa}$ and 33,5MPa. Figure (9) below depicts Millettia Laurentii creep curves under different stress levels. 


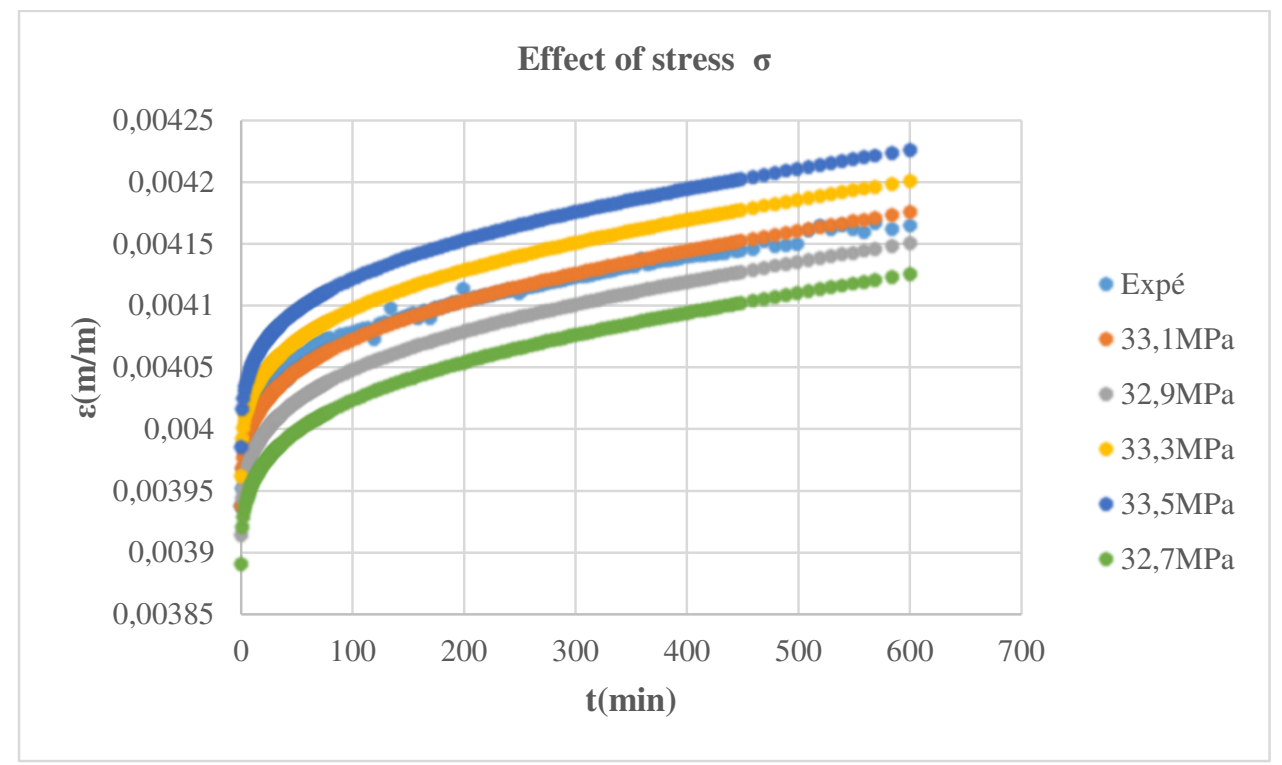

Figure 9 : Effect of stress level on creep process of Millettia Laurentii

The deformation of Millettia Laurentii is seriously affected by the stress level, and the deformation will increase in proportion as the stress will increase. However, the stress has no significant effect on the creep rate. The higher the stress level, the greater the instantaneous elastic deformation, and the shorter the time required to enter secondary creep at a constant velocity. These outcomes are consistent with the works of Njankouo et al. [30] et Zhou et al. [31] about the influence of stress level on wood creep process.

\subsection{Influence of the fractional derivative order $n$}

To study the influence of the fractional order, the variable control method is made use to ensure that other parameters remain fixed. The fractional order is progressively incremented from 0,357 to 0,369 by 0,003 step resulting in a series of creep curves with different orders, as figure 10 shows below.

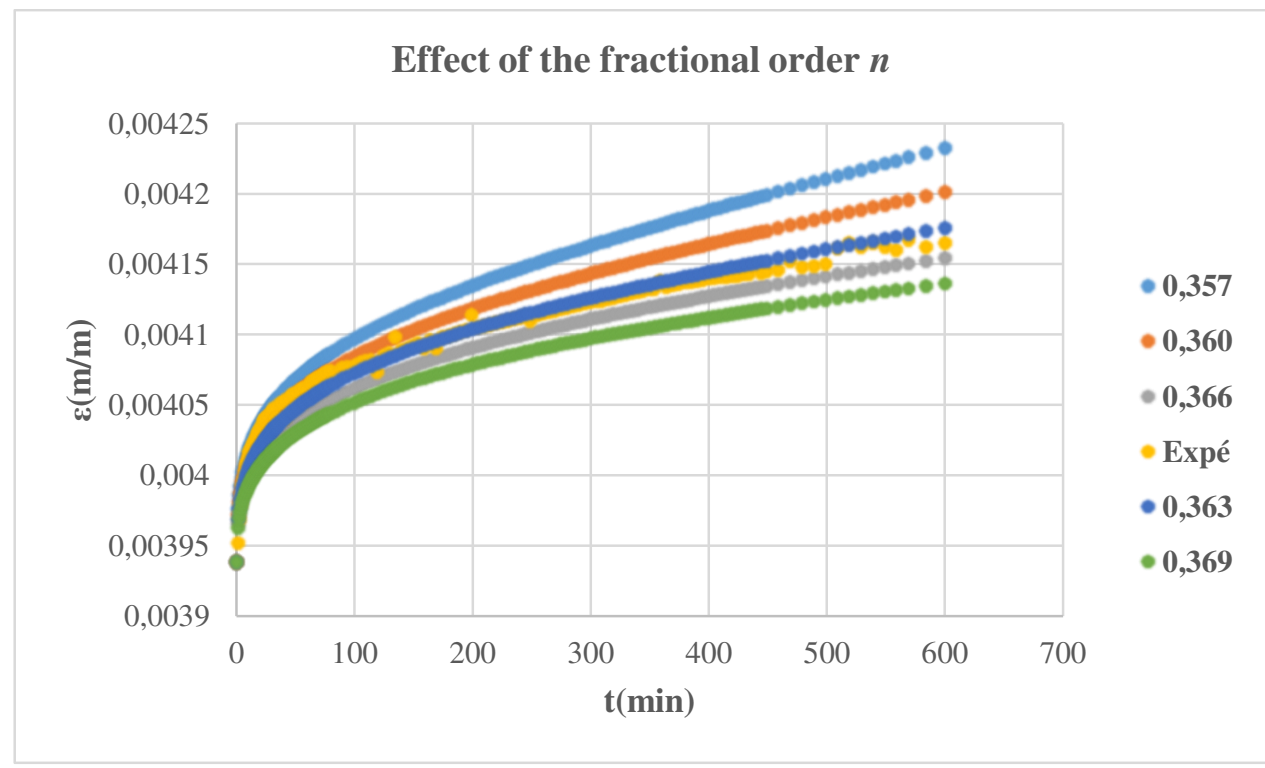

Figure 10 : Influence of the fractional order on creep process of Millettia Laurentii 
From figure 10, it is straightforward that increasing the fractional order increases the duration of primary and secondary creeps. The deformation of Millettia Laurentii decreases in proportion as the fractional order is incremented. In addition, creep rate is influenced by the fractional order; that is, the greater the fractional order, the smaller the creep rate at each level. This observation is the main finding of this experimental work, since it is not consistent with the outcomes of Zhou et al. [31, 32] concerning the effect of fractional order. As a matter of fact, Zhou et al. [31, 32] discovered that increasing fractional order resulted in a growth of the material deformation.

\section{Conclusion}

In this research work, fractional calculus theory has been applied to better study the nonlinear creep of Millettia Laurentii and to better follow creep phenomenon in engineering. The proposed fractional model has been verified and validated through creep tests on Millettia Laurentii wood specimens, these tests equally permitted the sensitivity analysis of parameters. The outcomes being that: The fractional order equation characterizing nonlinear creep of Millettia Laurentii wood has been studied and the methodology of determination of the model parameters has also been detailed. The creep model of Millettia Laurentii wood we developed and proposed in this work has been validated at several stress levels. The results revealed that fractional Zener model can well describe the two first phases of creep phenomenon, and it could be used as a reference for nonlinear creep of wood. The sensitivity analysis of model parameters has been done mainly through $\sigma$ and $\mathrm{n}$ parameters. From the results, it is obvious that the stress is positively correlated with the deformation and the creep rate of Millettia Laurentii wood while the fractional order is rather negatively correlated with the deformation and the creep rate of this wood species. The deformation and the creep rate will grow with the increase of $\sigma$ whereas they will have rather a decreasing shape with the increase of $n$. In future prospects, the stress levels employed in this work were not up to the third of ultimate breaking stress of Millettia Laurentii wood, the study of nonlinear behavior of this wood species under higher stress levels will be full filled in the upcoming research works. The proposed model in this work will undergo a modification with an element that will take into account the evolution of the material towards failure point.

\section{Abbreviations}

ABS : Average Braking Stress of Millettia Laurentii wood in Megapascals (MPa)

$\boldsymbol{\sigma}:$ Stress in Megapascals (MPa);

$\boldsymbol{\varepsilon}:$ Deformation in meter per meter $(\mathbf{m} / \mathbf{m})$

$\mathbf{E}_{\mathbf{0}}$ et $\mathbf{E}$ : Young Modulus en (MPa)

$\boldsymbol{\eta}^{\mathrm{n}}$ : Viscosity coefficient in (MPa.min $\left.{ }^{\mathrm{n}}\right)$

fig.: Figure 


\section{Acknowledgements}

The authors wish to express gratitude to Department of Physics, Mechanics and Modeling of Physical Systems Research Unit for providing the flexion testing facilities.

\section{Competing interests}

The authors declare that they have no competing interests

\section{Disclosure statement}

The authors report no financial interest or benefit that has arisen from a direct application of this research.

\section{Additional information}

\section{Funding}

No fund was reported for this research work.

\section{Authors' contribution}

Atchounga wrote the manuscript, performed the experiment of the study and was responsible for data collection. All authors conceived and designed the experiments, analyzed the data read and approved the final manuscript.

\section{References}

[1] Hung, K. C.; Wu, J. H. (2018). Effect of $\mathrm{SiO}_{2}$ content on the extended creep behavior of $\mathrm{SiO}_{2}$ based wood-inorganic composites derived via the sol-gel process using the stepped isostress method. Polymers, 10, 409.

[2] Hung, K. C., Tung, L. W. \& Wu, J. H. (2019). Long-Term Creep Behavior Prediction of Sol-Gel Derived SiO2- and TiO2-Wood Composites Using the Stepped Isostress Method. Polymers, 11, 1215.

[3] Gerhards CC (1977). Effect of duration and rate of loading on strength of wood and wood-based materials. U.S. Department of Agriculture, Madison.

[4] Kretschmann DE (2010). Wood handbook: wood as an engineering material. Forest Products Laboratory, Madison.

[5] Vincent, P., Bardet, S., Tordjeman, P., Gril, J. (2006). Analysis of viscoelastic properties of green Poplar in torsion. In: Proceedings of the International Conference on Integrated Approach to Wood Structure, Behaviour and Application. Joint meeting of ESWM and COST Action E35, Macchioni. Florence, Italy. Ed. Fioravanti, M. pp. 155-160.

[6] Holzer, M. S., Loferski, R. J. \& Dillard, A. D. (1989). A review of creep in wood: concepts relevant to develop long-term behavior predictions for wood structures. Wood and Fiber science, 21(4), pp. 376-392.

[7] Hunt DG (1999). A unified approach to creep of wood. Proc R Soc Lond A 455:4077-4095.

[8] Moutee, M., Fafard, M., Fortin, Y. et Laghdir, A. (2005). Modeling the creep behavior of wood cantilever loaded at free end during drying. Wood Fiber Sci 37(3):521-534.

[9] Moutee, M. (2006). Modélisation du comportement mécanique du bois au cours du séchage. Thèse de doctorat ph.D, Université Laval, Canada. 
[10] Kollman FFP, Côté WA Jr (1968). Principles of wood science and technology I, solid wood. Springer, Berlin.

[11] Morlier P, Palka LC (1994). Modelling of time-dependent deformation. Creep in timber structures. E \& F, Spon, London.

[12] Schniewind AP, Barrett JD (1972). Wood as a linear viscoelastic material. Wood Sci Technol 6:43-57.

[13] Tschoegl NW (1989). The phenomenological theory of linear viscoelastic behavior: an introduction. Springer, Berlin.

[14] Mohammad, M. H., Falk, K. W., Stefan, H. \& Hans, J. H. (2014). Rheological Model for Wood. Computational Physics for Engineering Materials. Pp. 1-37.

[15] Moutee, M., Fortin, Y. et Fafard, M. (2006). A global rheological model of wood cantilever as applied to wood drying. Wood Sci. Technol.

[16] Huč, S., Svensson, S. (2018). Coupled two-dimensional modelling of viscoelastic creep of wood. Wood Sci Technol 52(1):29-43.

[17] Ożyhar T, Hering S, Niemz P (2013). Viscoelastic characterization of wood: time dependence of the orthotropic compliance in tension and compression. J Rheol 57:699-717.

[18] Green DW, Winandy JE, Kretschmann DE (1999). Mechanical properties of wood. Forest Products Laboratory, Madison.

[19] Brokans, A. \& Ozola, L. (2014). Behaviour of creep of timber beams under natural environmental conditions. WIT Transactions on The Built Environment, Vol 137. Pp. 479-489.

[20] Navi P, Stanzl-Tschegg S (2009). Micromechanics of creep and relaxation of wood. A review. Holzforschung 63:186-198.

[21] Eder, M., Burgert, I., Tschegg, S. (2006). Relaxation experiments on wood fibres and tissues. In: Proceedings of the Third International Conference of the European Society for Wood Mechanics, FCT, Vila Real, Portugal. Eds. Morlier, P., Morais, J., Dourado, N. pp. 141-147.

[22] Zhuoping, S. (2005). The variable parameter rheological model of wood. Wood Sci. Technol. 39(1):19-26.

[23] Sherief, H. H., El-Sayed, A. M. A. (2010). Fractional order theory of thermoelasticity. Int. J. Solids Struct., 47 269-275.

[24] Koeller, R. C. (1984). "Applications of fractional calculus to the theory of viscoelasticity," Journal of Applied Mechanics, vol. 51, no. 2, pp. 299-307.

[25] Bagley, R. L. and Torvik, P. J. (1986). "On the fractional calculus model of viscoelastic behavior," Journal of Rheology, vol. 30, no. 1, pp. 133-155.

[26] Papoulia, K. D., Panoskaltsis, V. P., Kurup, N. V., Korovajchuk, I. (2010). Rheological representation of fractional order viscoelastic material models. Rheol. Acta, 49, 381-400.

[27] Mainardi, F and Spada, G. (2011). Creep, relaxation and viscosity properties for basic fractional models in rheology. European Physical Journal, vol. 193. pp. 133-160.

[28] Ramirez LES, Coimbra CFM. (2007). A variable order constitutive relation for viscoelasticity. Ann Phys 16:543-552. 
[29] Foadieng, E.; Atchounga, K. P.; Talla, P. K. Fractional calculus approach to investigation of creep behavior of Wengé Wood (Millettia Laurentii). International Journal of Innovative Science, Engineering \& Technology 2019, Vol. 6 Issue 8, 58-68.

[30] Njankouo Jacques Michel, Atchounga Kuida Prisca, Foadieng Emmanuel, Kamdjo Gregoire, Talla Pierre Kisito. Investigation of Physical, Mechanical Properties and Long-Term Creep Behavior of Wenge Wood (WW). Applied Engineering. Vol. 4, No. 2, 2020, pp. 27-34. doi: 10.11648/j.ae.20200402.11

[31] Zhou H.W., Wang C.P., Mishnaevsky L. Jr., Duan Z.Q. and Ding J.Y. (2013). A fractional derivative approach to full creep regions in salt rock. Mech Time-Depend Mater 17:413-425 DOI 10.1007/s11043-012-9193-x.

[32] Cong Zhang, Zhende Zhu, Shu Zhu, Zhilei He, Duan Zhu, Jinzhong Liu, Songsong Meng. Nonlinear Creep Damage Constitutive Model of Concrete Based on Fractional Calculus Theory. Materials 2019, 12(9), 1505; https://doi.org/10.3390/ma12091505. 
Figures

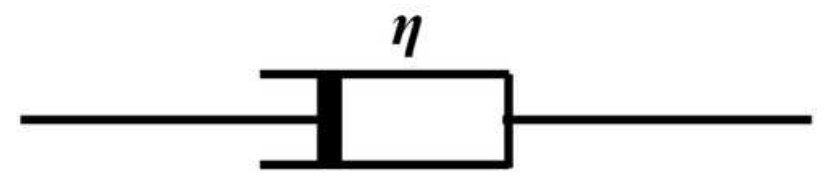

(a)

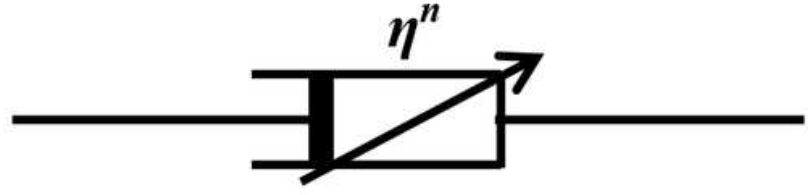

(b)

Figure 1

(a): Newton dashpot; (b): Spring-pot

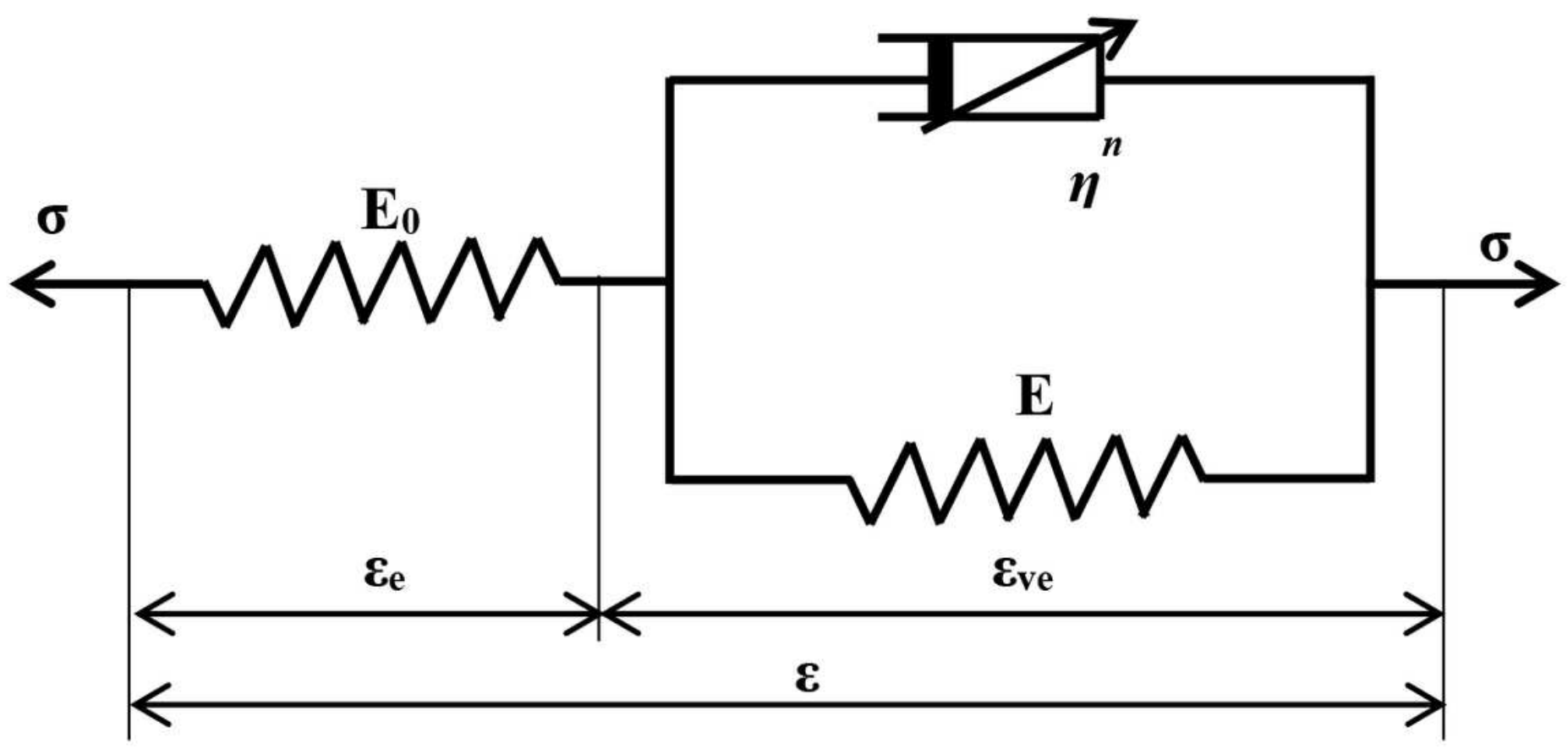

Figure 2

Fractional rheological Zener model 


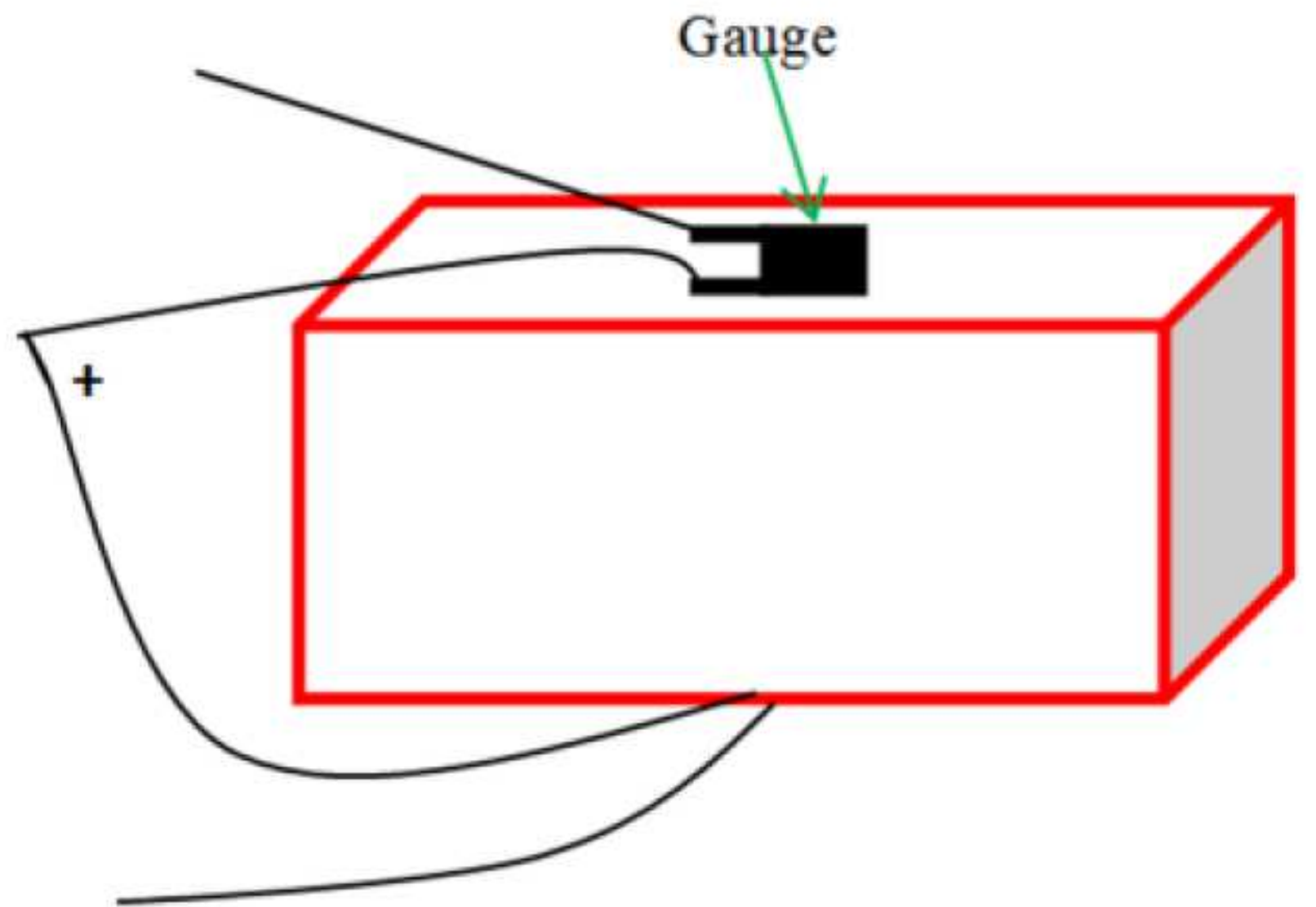

Figure 3

Sample carrying two gauges. 


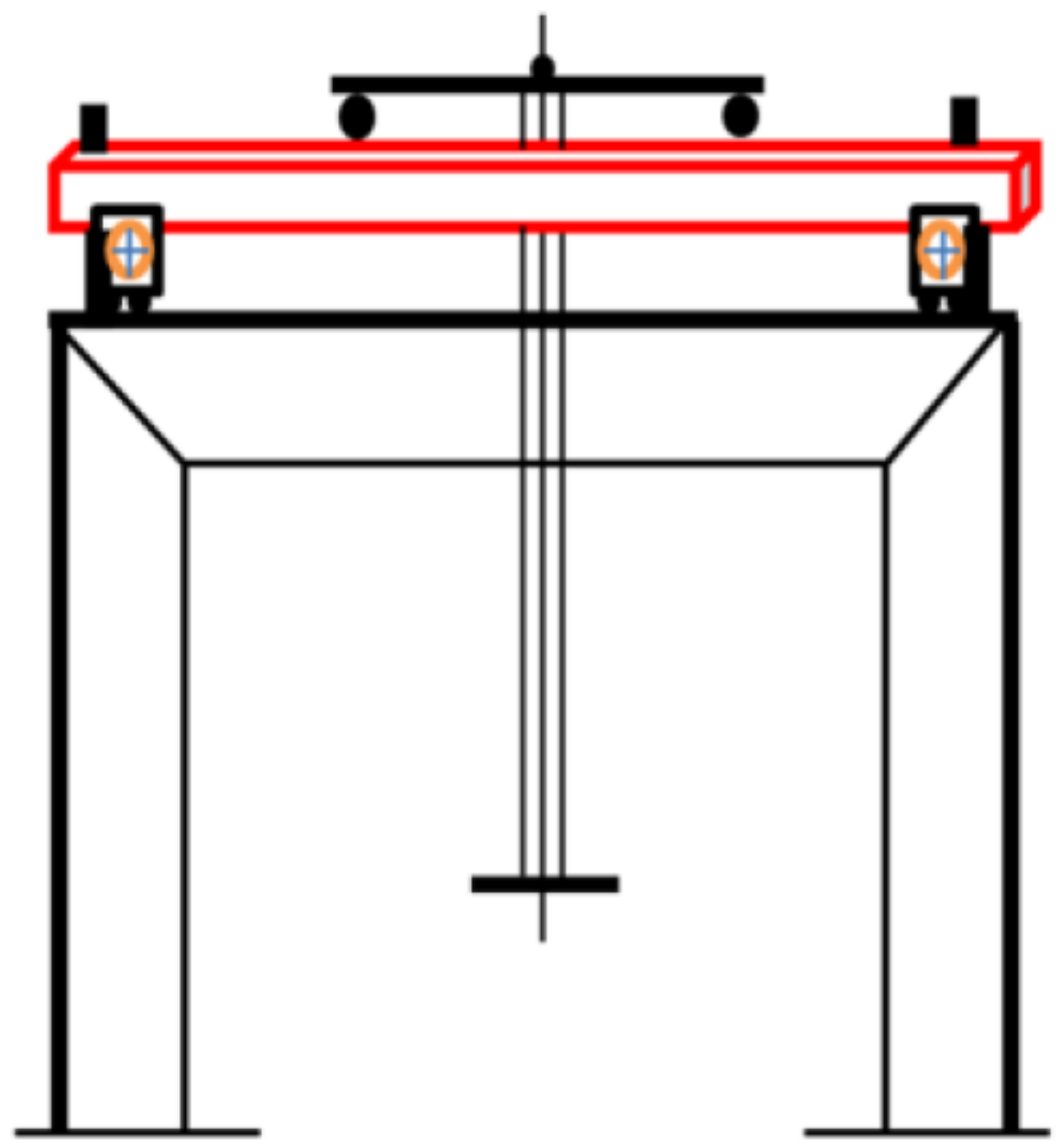

Figure 4

Creep test machine 
(a): $\sigma=38,06 \mathrm{MPa}$

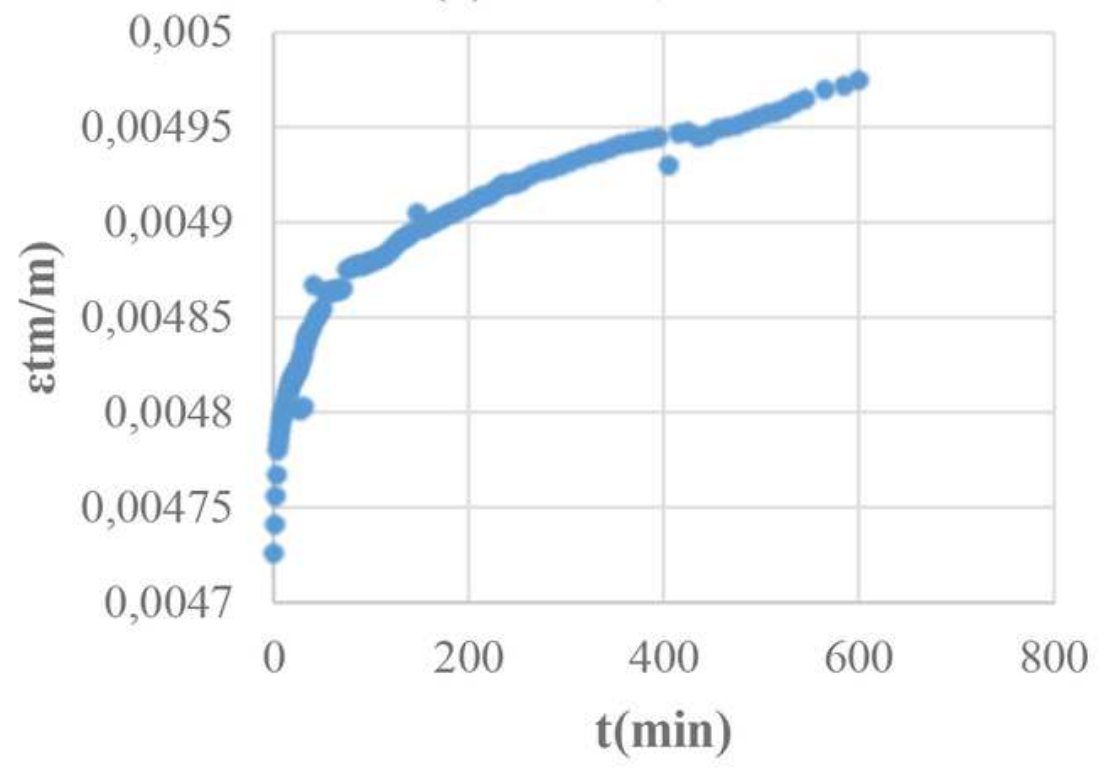

(b): $\sigma=43,03 \mathrm{MPa}$

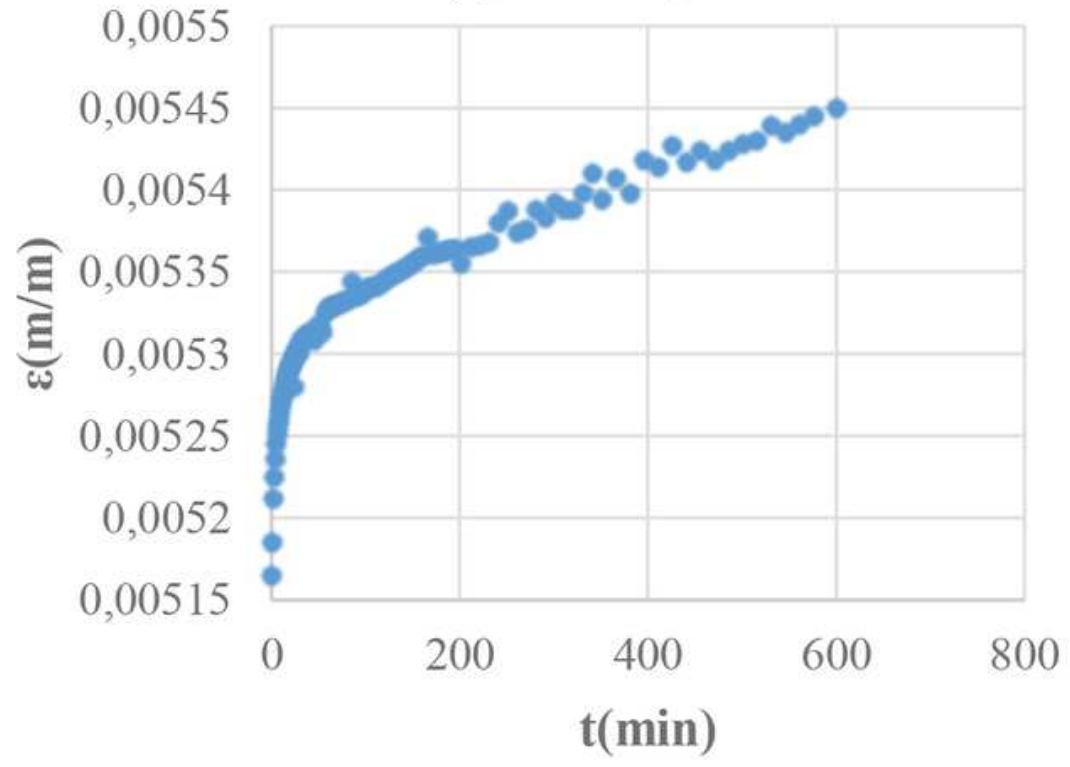

Figure 5

The curve of the wood creep tests under different stresses 
(a) $\sigma=38,06 \mathrm{MPa}$

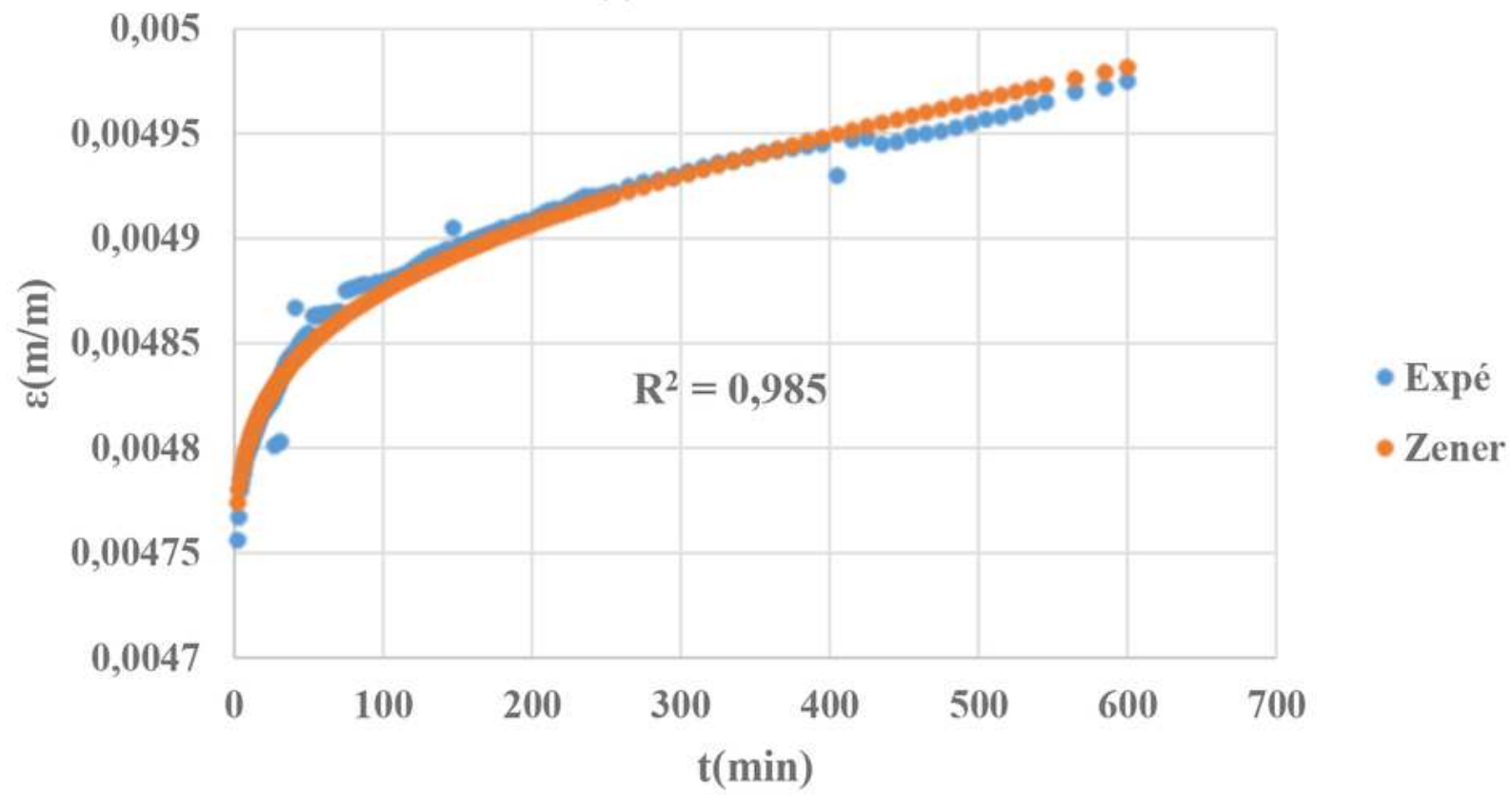

(b) $\sigma=43,03 \mathrm{MPa}$

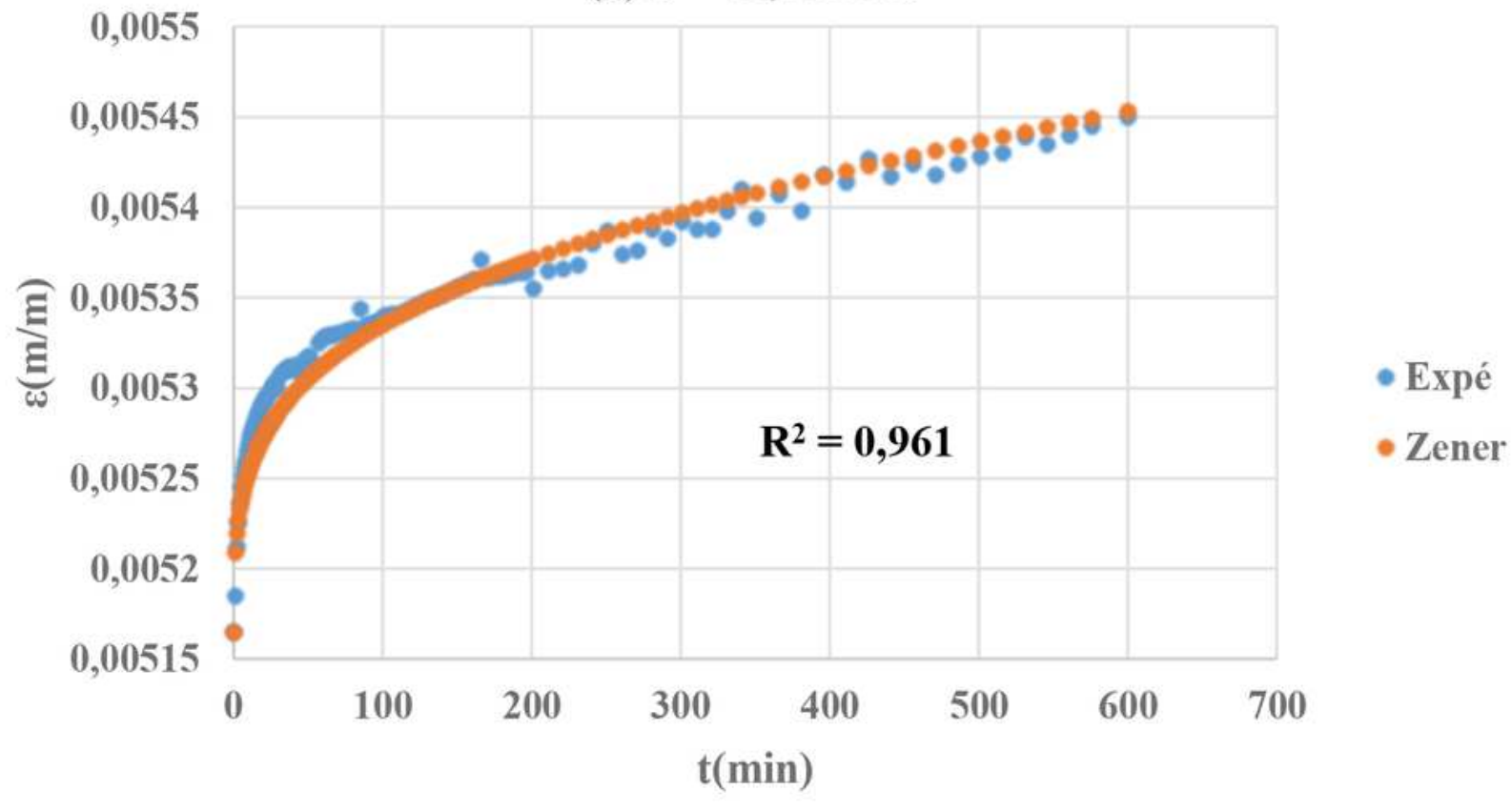

\section{Figure 6}

Experimental and Zener fractional forecasting curves at (a) 38,06 MPa et (b) 43,03 MPa 

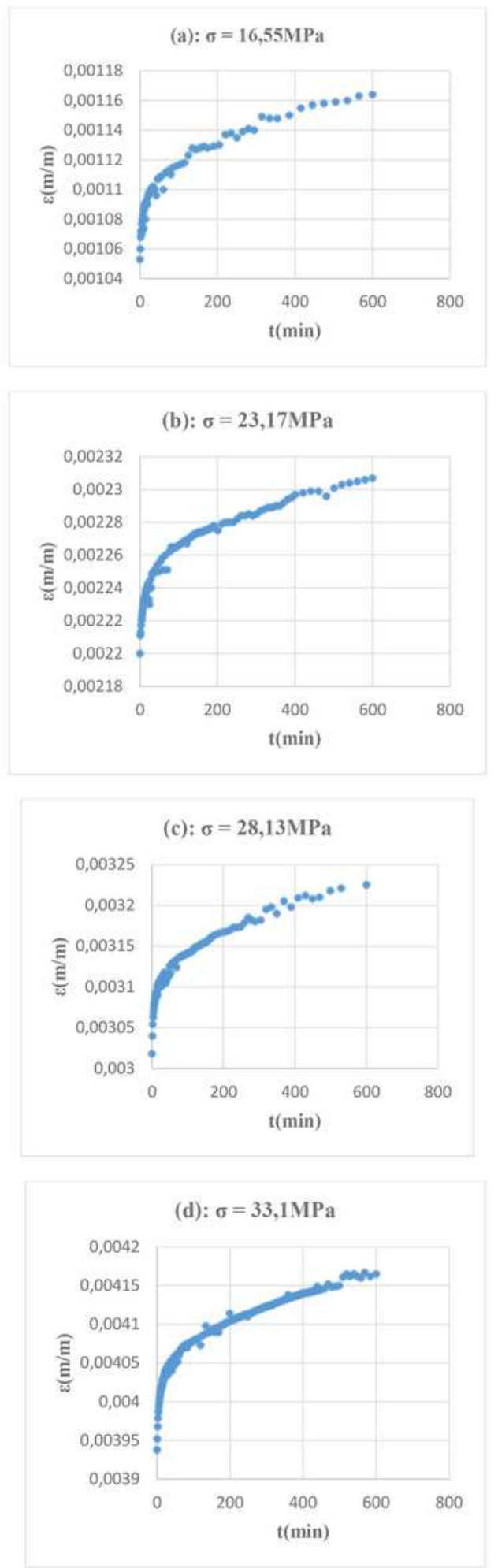

\section{Figure 7}

Courbes de fluage du bois Wengé sous différentes contraintes. (a) 16,55 MPa; (b) 23,17 MPa; (c) 28,13 $\mathrm{MPa}$ et (d) 33,1 MPa. 

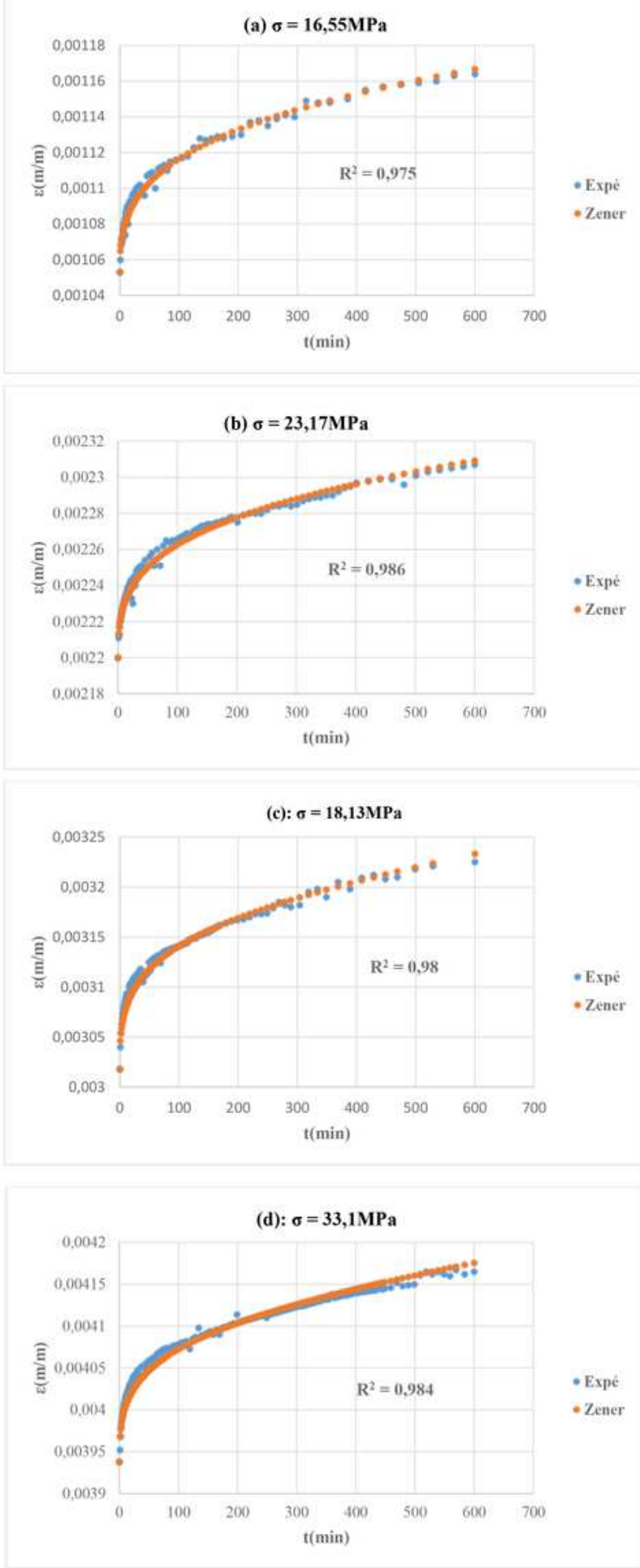

\section{Figure 8}

Experimental curves and forecasting curves of Millettia Laurentii wood. (a) 16,55 MPa; (b) 23,17 MPa; (c) $28,13 \mathrm{MPa}$ and (d) 33,1 MPa. 


\section{Effect of stress $\sigma$}

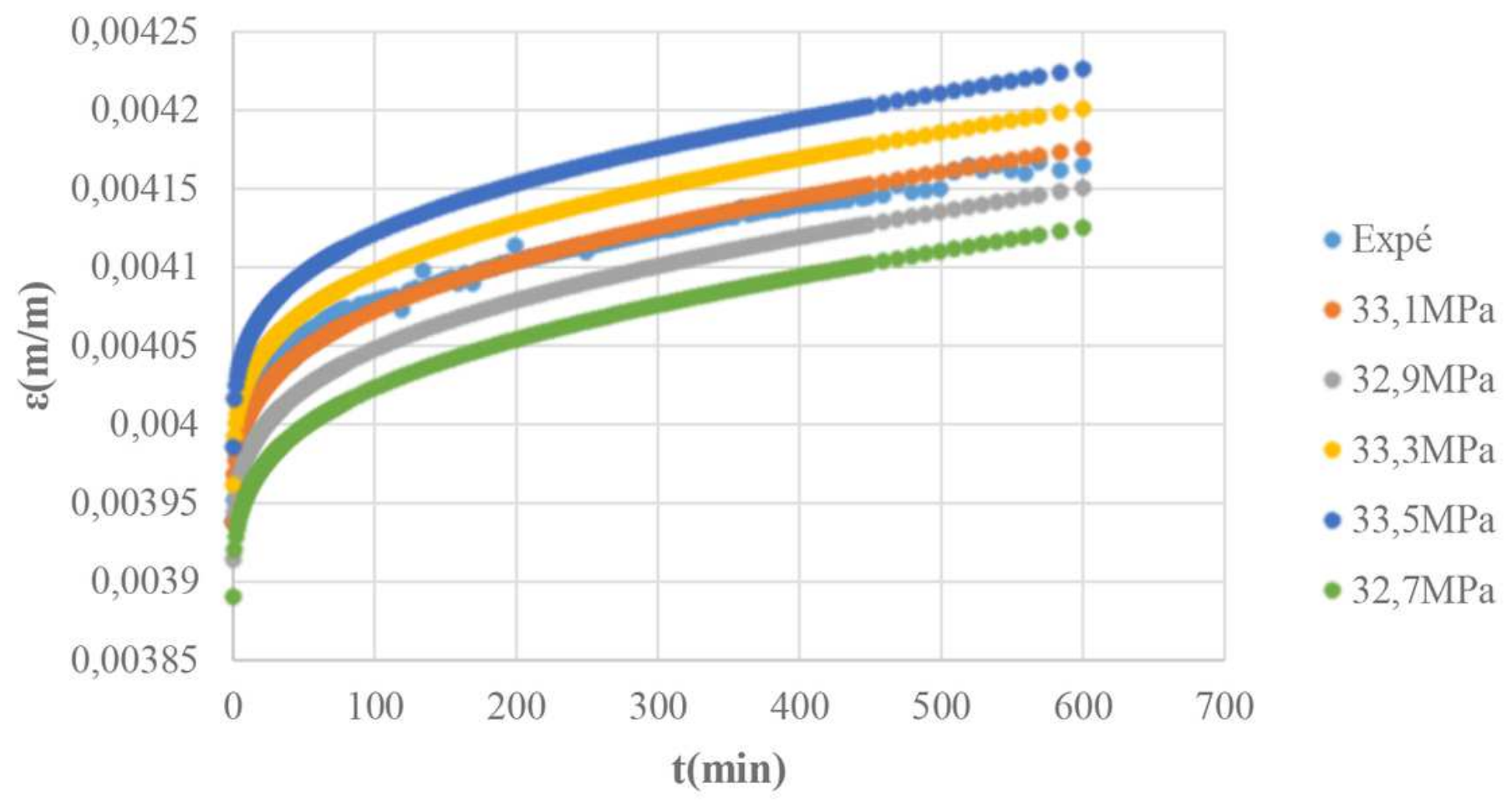

Figure 9

Effect of stress level on creep process of Millettia Laurentii 


\section{Effect of the fractional order $n$}

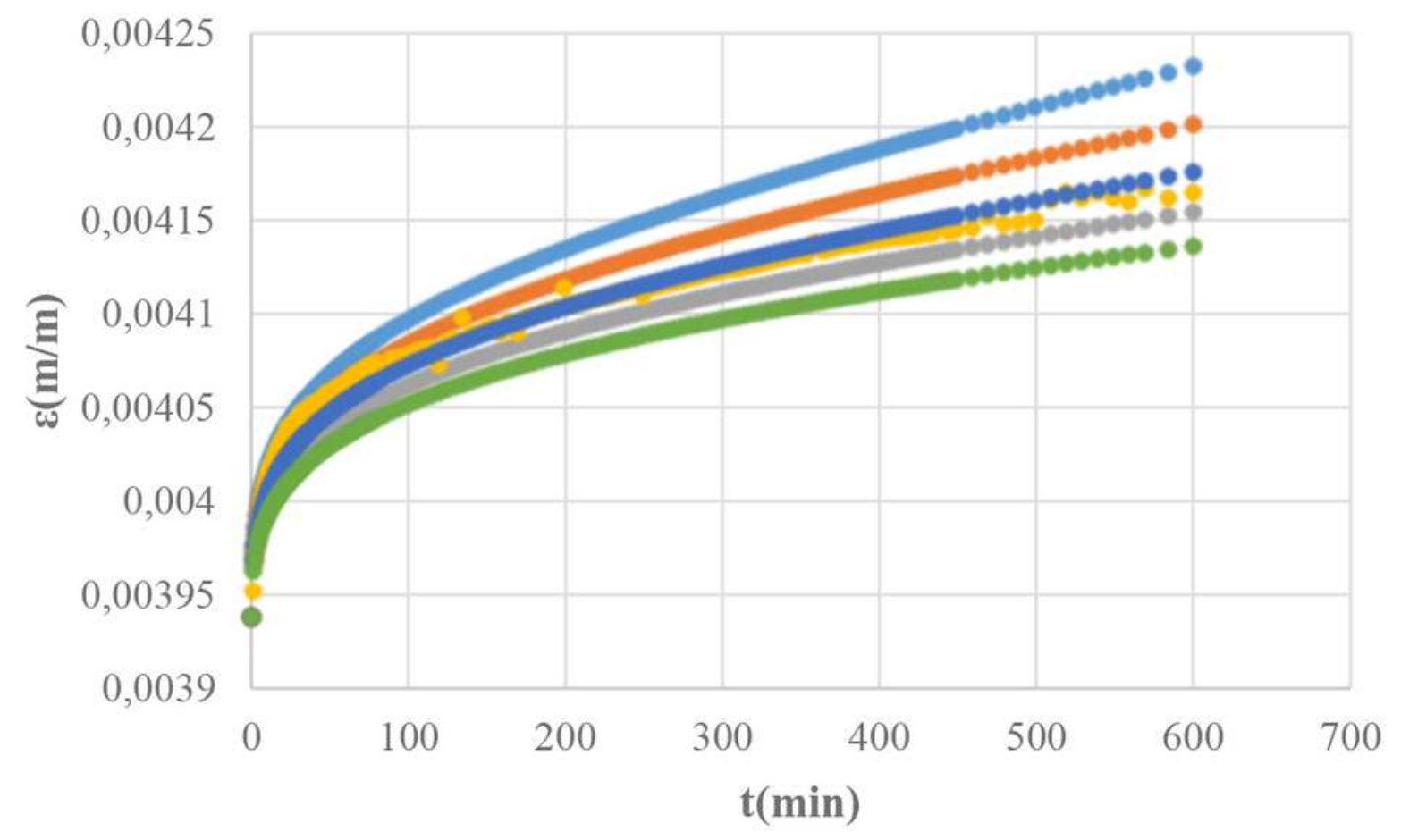

$\bullet 0,357$

$\bullet 0,360$

$\bullet 0,366$

- Expé

$\bullet 0,363$

$\bullet 0,369$

\section{Figure 10}

Influence of the fractional order on creep process of Millettia Laurentii 